\title{
Hand Hygiene Training and Its Impact on the Knowledge of Undergraduate Nursing Students in Kosovo
}

\author{
Idriz Sopjani ${ }^{1}$, Patrick Jahn ${ }^{2} \&$ Johann Behrens ${ }^{3}$ \\ ${ }^{1}$ Nursing Faculty of College AAB, Pristine, Kosovo \\ ${ }^{2}$ University Clinical Center Halle Saale, Germany \\ ${ }^{3}$ University of Martin-Luther Halle-Wittenberg, Germany \\ Correspondence: Idriz Sopjani, Nursing Faculty of College AAB, Pristine, Kosovo. E-mail: \\ idriz.sopjani@universitetiaab.com
}

Received: February 8, 2017 Accepted: February 23, 2017 Online Published: March 8, 2017

doi:10.5539/gjhs.v9n4p142 URL: https://doi.org/10.5539/gjhs.v9n4p142

\begin{abstract}
Background: Hand hygiene ( $\mathrm{HH}$ ) performing is a must in health care settings because it affects the human lives. Health Care Workers (HCW) must be aware and be trained continuously as regards hand hygiene.

Aim: The aim of this article was to evaluate and compare the knowledge before and after an educational training of undergraduate nursing students at an educational institution in Pristine, Kosovo.
\end{abstract}

Methods: A pre- post survey was conducted in February 2016 at an educational institution in Pristine, Kosovo. The World Health Organization (WHO) questionnaire for hand hygiene knowledge of Health Care Workers (HCW) was used to collect the data.

Results: From a total of 100 students, only $13(13 \%)$ were men and $87(87 \%)$ were women. Their ages ranged between 18-23 years old. Only 55 (55\%) had poor knowledge level, $42(42 \%)$ had moderate knowledge level and only $3(3 \%)$ had good knowledge about $\mathrm{HH}$ practices before the training and after the training only $1(1 \%)$ participant was found with poor knowledge, 61 (61\%) moderate knowledge and 38 (38 \%) good knowledge. The training had a significant impact on the acquisition of HH' knowledge. This was shown by the significant difference between the total points before and after the training $(\mathrm{p}<0.001)$.

Conclucion: The training should be done consistently and be part of the nursing school curriculum, maintaining a satisfactory level of knowledge about hand hygiene as these students in a near future will face with Hand Hygiene $(\mathrm{HH})$ issues in their daily clinical work.

Keywords: hand hygiene, undergraduate nursing students, WHO Multimodal Strategy, hand hygiene training

\section{Introduction}

Hand hygiene (HH) remains a very sensitive topic for the importance it possess. HH affects people's lives, so health care workers (HCW) should be aware about it and adopt the HH culture in their daily work. The HCW's compliance with $\mathrm{HH}$ guideline vary between $5 \%-89 \%$, but in most cases with an average value below $50 \%$. (WHO, 2009; Lankford et al., 2003; Pittet et al., 2000) The undergraduate nursing students were the focus of this study who must possess the necessary professional knowledge before they put it into practice. For the implementation of training tool, the study was based on WHO campaign "Clean Care is Safer Care and Save Lives". One of the WHO multimodal strategies to increase awareness and knowledge about HH is the training about HH understanding and practices (WHO, 2009). Numerous authors have conducted studies to assess the HH knowledge of undergraduate students and their level of knowledge was rather low (Nair et al., 2014; Van de Mortel et al., 2010; Herbert et al., 2013; Feather et al., 2000; Thakker\&Jadhav, 2015; Garcia-Zapata et al., 2009; Kelcíkova et al., 2012). Therefore, the inclusion of $\mathrm{HH}$ in the undergraduate curriculum is considered an emergency issue (Chatterjee et al., 2015). On the other hand, by enriching the undergraduate curriculum, the formal training is considered a key component in generating and improving knowledge, therefore it must be offered on an ongoing basis (Sopjani, 2016a; 2016b). Due to poor existing literature in Kosovo, it was necessary to conduct a study of this nature around the hand hygiene concept and practices. This study was conducted to measure the level of knowledge pre and post training for a group of nursing students at an educational institution in Pristine, 
Kosovo.

\section{Methods}

\subsection{Study Design}

The design of this study consists of a pre-post survey. The research was based in the adoption of the WHO multimodal strategy "training tool" of the WHO campaign "Clean Care is Safer Care and Save Lives". The training was conducted in February of 2016. A total of 100 students underwent the training. The participants were informed about the purpose of training, they were required to complete the questionnaire before the training and the same questionnaire after the training. The training lasted 5 hours.

\subsection{Data Collection}

The WHO questionnaire for hand hygiene knowledge of $\mathrm{HCW}$ was used to collect the data. The questionnaire was accessed from the WHO guideline materials online that are accessible for all researchers. The questionnaire carried a set of questions with answers yes or no, true or false. The correct answers were marked by 1 point while the wrong answers by zero points. Maximum points were 25. The level of knowledge was categorized as follows: poor knowledge, moderate knowledge and good knowledge. The participants, whose scores were less than $50 \%$, were considered to have a poor knowledge; those with scores between $50-74 \%$ had moderate knowledge and those with more than $75 \%$ of correct answers had a good knowledge about hand hygiene.

\subsection{Data Analysis}

The data analysis was run in the statistical program SPSS version 20. The data were presented with their average values, standard deviations and percentages. Also, to evaluate the statistical significance of the training in improving the knowledge of undergraduate nursing students, it was extracted paired t-test. $\mathrm{P}<0.05$ was considered statistically significant.

\subsection{Ethical Issues}

The permission to conduct the training was undertaken by the competent authorities and the ethics committee.

\section{Results}

From a total of 100 students, only $13(13 \%)$ were men and 87 (87\%) were women. Their ages ranged between 18-23 years old.

Pre-post Hand Hygiene Knowledge has been summarized in the Table 1. Before the training, only 66 (66 \%) knew that HCW hands when not clean are the main route of cross-transmission of potentially harmful germs between patients in a health care facility and $76(78.4 \%)$ knew the correct answer after the training. In general, from the Table 1, it can be noticed an overall increased percentage of correct answers after the training. To better explain this improvement in other words, there was summarized in the Table 2 the level of knowledge pre and post training for all undergraduate nursing students. The training completely reversed the initial categorization of student's knowledge. From a poor knowledge level, students passed in a moderate level of knowledge after the training. Thus, the training had a significant impact on the acquisition of HH' knowledge. This is shown by the significant difference between the total points before and after the training $(\mathrm{p}<0.001)$ (Table 3$)$. 
Table 1. Pre-Post Hand Hygiene knowledge of undergraduate nursing students

\begin{tabular}{|c|c|c|}
\hline $\begin{array}{l}\text { Knowledge statements } \\
\text { (correct answers) }\end{array}$ & $\begin{array}{l}\text { Pre-training } \\
\mathrm{N}(\%)\end{array}$ & $\begin{array}{l}\text { Post-training } \\
\text { N (\%) }\end{array}$ \\
\hline $\begin{array}{l}\text { Which of the following is the main route of cross-transmission of potentially harmful germs } \\
\text { between patients in a health-care facility? (HCW hands when not clean) }\end{array}$ & $66(66 \%)$ & $76(78.4 \%)$ \\
\hline $\begin{array}{l}\text { What is the most frequent source of germs responsible for health care-associated infections? } \\
\text { (germs already present on or within the patient) }\end{array}$ & $54(55.7 \%)$ & $70(70.7 \%)$ \\
\hline \multicolumn{3}{|l|}{ Hand hygiene actions that prevent the transmission of germs to the patients? } \\
\hline a) Before touching a patient (yes) & $88(88 \%)$ & $93(93 \%)$ \\
\hline b) Immediately after a risk of body fluid exposure (no) & $37(37.4 \%)$ & $48(48 \%)$ \\
\hline c) After exposure to the immediate surroundings of a patient (no) & $42(42.9 \%)$ & $48(48 \%)$ \\
\hline d) Immediately before a clean/aseptic procedure (yes) & $74(78.7 \%)$ & $91(91 \%)$ \\
\hline \multicolumn{3}{|l|}{ Hand hygiene actions that prevent the transmission of germs to the health care worker? } \\
\hline a) After touching a patient (yes) & $79(81.4 \%)$ & $94(94 \%)$ \\
\hline b) Immediately after a risk of body fluid exposure (yes) & $72(73.5 \%)$ & $91(91.9 \%)$ \\
\hline c) Immediately before a clean/aseptic procedure (no) & $27(29.3 \%)$ & $35(35 \%)$ \\
\hline d) After exposure to the immediate surroundings of a patient (yes) & $54(56.3 \%)$ & $85(85.9 \%)$ \\
\hline \multicolumn{3}{|l|}{$\begin{array}{l}\text { Which of the following statements on alcohol-based hand rub and hand washing with soap } \\
\text { and water are true? }\end{array}$} \\
\hline a) Hand rubbing is more rapid for hand cleansing than hand washing (true) & $55(59.1 \%)$ & $80(80 \%)$ \\
\hline b) Hand rubbing causes skin dryness more than hand washing (false) & $30(30.6 \%)$ & $63(63 \%)$ \\
\hline c) Hand rubbing is more effective against germs than hand washing (true) & $40(41.2 \%)$ & $63(63.6 \%)$ \\
\hline $\begin{array}{l}\text { d) Hand washing and hand rubbing are recommended to be performed in sequence } \\
\text { (false) }\end{array}$ & $16(17.2 \%)$ & $42(42 \%)$ \\
\hline $\begin{array}{l}\text { What is the minimal time needed for alcohol-based hand rub to kill most germs on your } \\
\text { hands? }(20 \mathrm{~s})\end{array}$ & $38(40 \%)$ & $71(71 \%)$ \\
\hline \multicolumn{3}{|l|}{ Which type of hand hygiene method is required in the following situations? } \\
\hline a) Before palpation of the abdomen (rubbing) & $34(34.7 \%)$ & $61(61 \%)$ \\
\hline b) Before giving an injection (rubbing) & $33(36.3 \%)$ & $59(59 \%)$ \\
\hline c) After emptying a bedpan (rubbing) & $19(20 \%)$ & $57(57 \%)$ \\
\hline d) After removing examination gloves (rubbing) & $22(22.2 \%)$ & $56(56 \%)$ \\
\hline e) After making a patient's bed (rubbing) & $30(30 \%)$ & $72(72 \%)$ \\
\hline f) After visible exposure to blood (washing) & $77(80.2 \%)$ & $95(96 \%)$ \\
\hline \multicolumn{3}{|l|}{$\begin{array}{l}\text { Which of the following should be avoided, as associated with increased likelihood of } \\
\text { colonization of hands with harmful germs? }\end{array}$} \\
\hline Wearing jewellery (yes) & $84(84.8 \%)$ & $93(93 \%)$ \\
\hline Damaged skin (yes) & $92(92 \%)$ & $94(94 \%)$ \\
\hline Artificial fingernails (yes) & $85(90.4 \%)$ & $93(93.9 \%)$ \\
\hline Regular use of a hand cream (no) & $42(42 \%)$ & $64(64 \%)$ \\
\hline
\end{tabular}


Table 2. Pre-Post level of knowledge of Hand Hygiene of undergraduate nursing students

\begin{tabular}{lll}
\hline & Pre Training & Post Training \\
\hline Poor & $55(55 \%)$ & $1(1 \%)$ \\
Moderate & $42(42 \%)$ & $61(61 \%)$ \\
Good & $3(3 \%)$ & $38(38 \%)$ \\
\hline
\end{tabular}

Table 3. Pre-Post comparison of knowledge score

\begin{tabular}{llll}
\hline & Mean \pm SD & N & P \\
\hline Pre Score & $12.65 \pm 2.6$ & 100 & $<0.001^{*}$ \\
Post Score & $17.73 \pm 2.7$ & 100 & \\
\hline
\end{tabular}

\section{Discussion}

The overall scores before the training were low and after the training were moderate similar to other studies (Thakker\&Jadhav, 2015; Ariyarathne et al., 2013). Thakker and Jadhav (2015) conducted a similar study to this and documented poor knowledge. Out of 40 nursing students, only $37.5 \%$ knew that unclean hands were the main route of transmission of potentially harmful germs (Thakker\&Jadhav, 2015). While in this study 66 (66\%) knew the correct answer before the training that unclean hands were the main route of transmission of potentially harmful germs and $76(78.4 \%)$ after the training. According to a similar study, only $14(35 \%)$ had poor knowledge, $24(60 \%)$ moderate knowledge and only $2(5 \%)$ had good knowledge (Thakker\&Jadhav, 2015). While in this study, 55 (55\%) had poor knowledge level, $42(42 \%)$ had moderate knowledge level and only $3(3 \%)$ had good knowledge about $\mathrm{HH}$ practices before the training and after the training only $1(1 \%)$ participant was found with poor knowledge, 61 (61\%) moderate knowledge and 38 (38\%) good knowledge. Another study assessed hand hygiene knowledge among medical students at a teaching hospital in India and found moderate knowledge similar to this study (Chatterjee et al., 2015). Thus, out of 191, 145 (75\%) had moderate knowledge, 15 (8\%) had good knowledge and the rest 31 (16\%) had poor knowledge (Chatterjee et al., 2015). Many other authors who conducted comparison study of HH knowledge among medical and nursing students, have found that in general nursing students had significantly higher knowledge than medical students (Nair et al.,2014; Van de Mortel et al., 2010; Chatterjee et al., 2015; Ariyarathne et al., 2013). A poor knowledge level was stated before the training. This may be linked to the lack of attention of the educational institutions for the inclusion of hand hygiene topics in the nursing school curriculum. WHO guideline recommendations regarding $\mathrm{HH}$ are included in the school curriculum of many countries. Therefore, the nursing school curriculum in educational institutions in Kosovo must be enriched and updated with WHO materials about HH. An effective educational program, in the context of formal training and the nursing school curriculum, is very important due to the fact that the poor knowledge and low HH practical skills among students may have a significant negative impact in the HH compliance later in their daily clinical work (Kelcíkova et al., 2012). Similar to this study, Huang et al., (2012) assessed the impact of an educational program and found a significant increase of knowledge $(\mathrm{p}<0.001)$ but for a longer period of time $(4$ months) and with two groups (experimental and control). While Goud \& Chamberlain (1997) found no significant impact of the 3-month educational program. The improve of training programs appears to be necessary in order to address gaps of knowledge, attitudes and practices of students as well as the establishment of best practice conditions that are eligible for future nurses (Ariyarathne et al., 2013).

\section{Conclusion}

This study was conducted with a limited sample size. A potential future study may consider a larger number of participants or a comparative study may be conducted between nursing students with other students of medical sciences. The pre and post overall scores stated a critical role of trainings in shaping students knowledge despite what they receive in the nursing school curriculum. Thus, the training should be done consistently and be part of the nursing school curriculum, maintaining a satisfactory level of knowledge about hand hygiene as these students in a near future will face with $\mathrm{HH}$ issues in their clinical daily work.

\section{Funding Sources}

This research did not receive any specific grant from funding agencies in the public, commercial, or not-for-profit sectors. 


\section{Competing Interests Statement}

All authors report no conflicts of interest relevant to this article.

\section{References}

Ariyarathne, M. H., Gunasekara, T. D., Weerasekara, M. M., Kottahachchi, J., Kudavidanage, B. P.,\&Fernando, S. S. (2013).Knowledge, attitudes and practices of hand hygiene among final year medical and nursing students at the University of Sri Jayewardenepura.Sri Lankan Journal of Infectious Diseases, 3(1).

Chatterjee, S., Mondal, T. K.., Sarkar, K., Shahbabu, B., Sarkar, I., Barik, G., et al. (2015).Assessment of Hand Hygiene Knowledge among Medical Students at a Teaching Hospital of India. Scholars Journal of Applied Medical Sciences, 3(6C), 2334-2339.

D'Alessandro, D., Agodi, A., Auxilia, F., Brusaferro, S., Calligaris, L., Ferrante, M., ...Righi E. (2014). Prevention of healthcare associated infections: Medical and nursing students' knowledge in Italy. Nurse education today, 28, 34(2), 191-5.https://doi.org/10.1016/j.nedt.2013.05.005

Feather, A., Stone, S. P., Wessier, A., Boursicot, K. A., \&Pratt, C. (2000).'Now please wash your hands': the handwashingbehaviour of final MBBS candidates.Journal of Hospital Infection, 45(1), 62-4.https://doi.org/10.1053/jhin.1999.0705

Garcia-Zapata, M. R., e Souza, A. C., Guimarães, J. V., Tipple, A. F., Prado, M. A., \&García-Zapata, M. T. (2009). Standard precautions: knowledge and practice among nursing and medical students in a teaching hospital in Brazil.International Journal of Infection Control.6(1).

Gould, D., \&Chamberlain, A. (1997).The use of a ward - based educational teaching package to enhance nurses' compliance with infection control procedures. Journal of clinical nursing. 6(1), 55-67.https://doi.org/10.1111/j.1365-2702.1997.tb00284.x

Herbert, V. G., Schlumm, P., Kessler, H. H., \&Frings, A. (2013).Knowledge of and adherence to hygiene guidelines among medical students in Austria.Interdisciplinary perspectives on infectious diseases.

Huang, J., Jiang, D., Wang, X., Liu, Y., Fennie, K., Burgess, J., \&Williams, A. B. (2002).Changing knowledge, behavior, and practice related to universal precautions among hospital nurses in China. The Journal of Continuing Education in Nursing, 33(5), 217-24.

Kelcíkova, S., Skodova, Z., \&Straka, S. (2012). Effectiveness of hand hygiene education in a basic nursing school curricula. Public Health Nursing, 29(2), 152-9.https://doi.org/10.1111/j.1525-1446.2011.00985.x

Lankford, M. G., Zembower, T. R., Trick, W. E., Hacek, D. M., Noskin, G. A., \&Peterson, L. R. (2003).Influence of role models and hospital design on hand hygiene of health-care workers. Emerging infectious diseases, 9(2), 217-23.https://doi.org/10.3201/eid0902.020249

Nair, S. S., Hanumantappa, R., Hiremath, S. G., Siraj, M. A., \&Raghunath, P. (2014). Knowledge, attitude, and practice of hand hygiene among medical and nursing students at a tertiary health care centre in Raichur, India. ISRN preventive medicine.

Pittet, D., Hugonnet, S., Harbarth, S., Mourouga, P., Sauvan, V., Touveneau, S., \&Perneger, T. V. (2000).Effectiveness of a hospital-wide programme to improve compliance with hand hygiene.The Lancet. 356(9238), 1307-12.https://doi.org/10.1016/S0140-6736(00)02814-2

Sopjani, I. (2016a). Health Care Personnel's Attitude toward Hand Hygiene in Regard to the Prevention of Health-Care Associated Infections: A Cross Sectional Study at the University Hospital Pristine. Open Journal of Nursing, 6(10), 841.https://doi.org/10.4236/ojn.2016.610083

Sopjani, I. (2016b). Training as an effective tool to increase the knowledge about hand hygiene actions. An evaluation study of training effectiveness in Kosovo. Medical Archives, 71(1), 16-19.doi: 10.5455/medarh.2017.71.16-19.

Thakker, V. S., \&Jadhav, P. R. (2015).Knowledge of hand hygiene in undergraduate medical, dental, and nursing students: A cross-sectional survey. Journal of family medicine and primary care.4(4), 582.https://doi.org/10.4103/2249-4863.174298

Van de Mortel, T. F., Apostolopoulou, E., \&Petrikkos, G. (2010).A comparison of the hand hygiene knowledge, beliefs, and practices of Greek nursing and medical students.American journal of infection control, 38(1), 75-7.https://doi.org/10.1016/j.ajic.2009.05.006 
World Health Organisation[WHO]. (2009). 'First Global Patient Safety Challenge Clean Care is Safer Care'. $\begin{array}{lccc}\text { Geneva: } & \text { WHO. } & \text { Retrieved } & \text { September } \\ \text { http://whqlibdoc.who.int/publications/2009/9789241597906_eng.pdf?ua=1 }\end{array}$

\section{Copyrights}

Copyright for this article is retained by the author(s), with first publication rights granted to the journal.

This is an open-access article distributed under the terms and conditions of the Creative Commons Attribution license (http://creativecommons.org/licenses/by/4.0/). 